\title{
Religious Miniature Books: \\ INTRODUCTION AND OVERVIEW
}

\author{
Kristina Myrvold and Dorina Miller Parmenter \\ Linnaeus University; Spalding University \\ kristina.myrvold@lnu.se; dparmenter@spalding.edu
}

Miniature books, handwritten or printed books in the smallest format, have fascinated religious people, printers, publishers, collectors, readers, and others throughout the centuries because of their unique physical features, and continue to do so today. The small lettering and the delicate pages, binding, and covers highlight the material form of texts and invite sensory engagement and appreciation. This thematic issue of Postscripts: The Journal of Sacred Texts and Contemporary Worlds addresses miniature books with focus on religious books considered sacred in Jewish, Christian, Muslim, Hindu, and Buddhist traditions. The volume is a result of the interdisciplinary workshop "Miniature Books: Production, Print, and Practice" that was held at Linnaeus University in Sweden during October 2016 and included researchers working in religious studies, book history, and art history. The aim of the workshop was to discuss empirical and theoretical issues related to the production, use, and material properties of miniature books in historical and contemporary contexts by starting from a perspective that combined religious studies with book history and explored how religious interests intersect with technological developments.

The discussions from the 2016 workshop and the articles collected in this volume reflect new perspectives on miniature religious books because until now, most of the available literature on miniatures has been written by book collectors. These collectors have contributed significantly to the understanding of the field with inventories of library holdings and catalogs of miniature books that identify and trace the histories of specific editions and present technical details of the books' physical formats (see for example: Adomeit 1980; Bromer and Edison 2007; Spielmann 1961; Welsh 1989). When discussing possible uses of miniature books, collectors have emphasized the practical function of texts that take up little space and can easily travel, lest we think that they exist only for humans' fascination with and appreciation for the craftsmanship required to produce tiny books (see for example: Bondy 1981, 3; Henderson 1933, 147; O’Donnell 1943, 177; Welsh 1987, 1). 
These contributions have opened up a niche for the articles in this volume as well as continued research on miniature books in the scholarly framework of material culture and religion that focuses on the circulation, exchange, and practices of material objects and how "things" can bear significant values and actively shape human behaviors and relations in various cultural contexts (Meyer et al. 2010; Morgan 2010). From this perspective on material culture, books are not just conveyers or containers of knowledge but their physical forms are sites of meaning, believed to affect the content, use, and experience of them. As material objects, they are always products of human collaboration and agency. When books store religious texts they may also be attributed with various cultural understandings of textuality and sacredness and presented as having a durable life beyond human contexts and agencies. Religious people ritualize both the content and the material form of religious books, which may be perceived to evoke and mediate supernatural powers when the books are used and displayed, resulting in veneration or worship. Even if religious books are rendered as "de-contextualized" with a fixed status detached from a ritual setting, they are sharable across temporal and spatial borders and continually involved in re-contexualizing processes that create new interpretations and meanings (Myrvold 2007, 2010; Veidlinger 2006). When religious books are miniaturized to the smallest format, several questions arise related to the intricate relationships between the content and the material form of the books and the religious status and use of them.

The definitions and classifications of small books have varied over time, but characteristic for all are attempts to decide the maximum size of a miniature. In the language of modern publishers and book historians who refer to a codex-format, a miniature book is equal to a 64mo (sexagesimo-quarto) which is the smallest size of a book when a standard uncut single sheet of paper is folded to have sixty-four pages (Welsh 1987, 5). Although collectors of miniature books have not always agreed, many have identified 7.6 centimeters or three inches as the maximum size in height and width for a book to be termed a miniature (Bondy 1981, 1; Welsh 1987, 9). As Anne Bromer and Julian Edison explained their more pragmatic definition, "if a book can fit roughly in the palm of a hand it is a miniature" (Bromer and Edison 2007, 51). These definitions also imply that the smallness of miniature books is only restricted by the material limitation and can be exposed to continued experimentation when interacting with new technologies. The arrival of various printing methods (for example, typography and later lithography and photo-lithography) allowed for producing books in 
considerably reduced size, some of which became a celebration of new technological inventions, and nanotechnologies in the twenty-first century have extended the borders of smallness and the criteria for what can be included in definitions of miniature books. This emphasis on size as the defining criterion follows Western conventions since it presumes a norm of printed books on paper in codex format; however, many diminutive books in history and different parts of the world have used diverse materials and formats for producing texts, such as scrolls, tablets, palm leaves, bones, wood, silk, and even nutshells. From the perspective of book historians, the word "book" may rather be used broadly to signify "an object that records an idea in coded form" (Stam 2010,26). A book is popularly associated with "codex" but, as a technical term, it may include various physical formats.

Throughout the history of books, texts of all kinds-religious (scriptures, prayer books, etc.) and secular (novels, dictionaries, almanacs, speeches, etc.)-have been created in miniature format. They have included luxury items crafted for people with power and prestige and mass-produced books sold for a shilling to common people. They have been produced for public display and admiration as well as for highly personal and private uses. Many of the diminutive books have been presented as tiny facsimiles, copies, or imitations of much larger original texts or they have included selected texts as a condensation of the original book and its semantic content. When reproducing small versions of authorized texts and presenting them in a similar, recognizable format to the larger prototypes, the miniature books can make appeals to traditions and authorities. As such, they become representations of the prototypical books that provide legitimacy to their owners and users. Yet by their smallness, the miniature books challenge the boundaries for legibility of texts and the users' access to the semantic content. The creation of clear and readable characters in the smallest handwriting or print often has been considered a sign of high quality of the books. Thus miniaturization simultaneously draws attention to material scale, the aesthetics of books, and the technologies and methods by which they are produced. The creation of books in the smallest format has involved experimentation and manipulation of the exterior forms and served as a demonstration of artistic skill among scribes, printers, and binders, expected to affect and impress potential users. In the case of religious texts, believed to be of otherworldly origin, it is especially important to reproduce exact and legible copies of the original texts that are accredited a sacred status, and the creation of these books in the smallest scale has even been considered an act of worship in itself. 
The various production methods of both small and large religious books reveal how religious traditions adopt divergent stances to the media and technology that are used for creating and transmitting texts, which also shape cultural conventions for the aesthetics of books. While some traditions (like Christianity) espoused letterpress printing early, others (such as Islam) were more restrictive to typographical print since it was considered disrespectful to sacred words and instead favored handwritten manuscripts and later lithographic print which enabled a continuation of the manuscript culture. The use of letterpress printing followed, in a modified form, European typographic conventions for what constituted an aesthetically acceptable book, whereas lithography enabled appearances that provided legitimacy to printed books in cultures that valued scribal and calligraphic traditions (see for example: Myrvold 2017; Shaw 1994; Stark 2009; Yelle 2013). In many traditions, the norms guiding the aesthetics of larger books seem to have been followed on the smallest copies as well, sometimes by using complementary technologies. The introduction of photomechanical reproduction of texts in the nineteenth century could combine different technologies in the production and led to the increased popularity and mass-production of miniature books. The effects of these technological inventions transformed the books into commodities for the masses and altered the methods for their distribution, acquisition, and use.

Miniature books, and especially diminutive religious books, are often mentioned as interesting curiosities by collectors and practitioners alike, but have seldom been exposed to detailed research studies. The articles in this volume serve to fill this gap and pay special attention to the purposes and functions of producing and using religious miniature books in shifting historical and cultural contexts. In many cases, there are very few sources available to researchers and little is known about the actual uses of or performances with the small books by those who have purchased or possessed them. Often the material properties of the books, such as their print, illustrations, and covers, stand as the only sources available for information. Producers have sometimes addressed the books' functions by adding specific paratextual features to them, like written instructions and images within the books that signal how readers should ideally approach them. As with larger books, conscious choices of the writing or print systems, orthographies, and paratextual features convey social meanings and, when specific forms of books become stipulated, the books may even represent collective identities, religions, and nations (Genette 1997; Jaffe et al. 2012). The 
books may further include different paraphernalia, like bookmarks, key or neck chains, and magnifying glasses, which indicate possible uses. Given the small scale, many explanations for their use frequently point to practicality of portability and textual intimacy, in the sense that the books may be brought for travels and can be carried close to the body. In the heyday of miniature books during the nineteenth century, with the mass production of books and the availability of new kinds of travel through the railway system, practical explanations like these probably projected visions of a new modern and mobile lifestyle in company with one's favorite or most venerated book. Other explanations for the uses of miniature religious books refer to their apotropaic and amuletic functions to protect, bring luck, and ward off misfortunes.

Religious books, as both texts and material objects, do not have any intrinsic quality, nature, or meaning outside of a social and relational context, but are attributed meanings and functions when humans are interacting with them. The efficiency and power that religious people ascribe to objects like religious books are often reinforced by means of ritual performances with and care of the objects. Within the religious traditions there usually exists a wide range of prescriptions and normative practices for the uses of religious books and it is often expected that the miniaturized versions should be given a treatment similar to their larger prototypes. Since miniaturization emphasizes the material aspects of books, many articles in this volume discuss the iconic dimension and how religious books are presented as material objects or artifacts. In an effort to further research on the social functions of books, James W. Watts has presented a theory about the ritualization of their semantic, performative, and iconic dimensions. According to Watts, religious books can be understood in terms of a ritualization that formalizes their uses. While the semantic dimension refers to different ways of interpreting the content that may create power and authority through ritualization, the performative dimension signifies different enactments of texts, ranging from recitation to dramatization, that can provide religious inspiration. The iconic dimension is expressed in the physical forms of books that convey religious significance and are used for legitimizing purposes. Religious scriptures are given special material properties that distinguish them from other books and can be manipulated in various social and political contexts to legitimize persons, institutions, and regimes by linking them to religious authority. Often all the three dimensions are ritualized in culturally different ways, but printing technologies have come to emphasize the iconic dimension: religious scriptures can act as powerful material

(C) Equinox Publishing Ltd 2019 
symbols for cultures, religions, and nations, and give their users, owners, and patrons power and legitimacy (Watts 2006). From this theoretical framework, several articles in this volume discuss how miniature books, as iconic material objects in the smallest format, may evoke sensual interaction when they are ritually displayed, create remembrance of the religious attitudes that should be given to their larger prototypes, and may function to structure and index social statuses, identities, and power relations when they are used and exchanged.

\section{Overview of the articles}

This volume includes nine chapters that address the format and function of religious miniature books. In the opening article, James Watts suggests that the distinctive form of miniature books provides a concentrated emphasis on the ritualization of the iconic dimension of books. Starting from his theory on the three dimensions of scriptures, he argues that miniature books are not only read, interpreted, and performed (the semantic and performative dimensions), but a sustained attention to the size of these books invites people to engage with them as visual and material objects. This opens up different ways of ritualizing the iconic dimension which then invokes rhetoric related to the books as mass produced, personal texts. Miniature books thus represent distinctions between public and private spheres of power while also offering those with relative social disempowerment a sense of legitimacy and prestige in their personal practices.

Focusing on the functions of miniaturized religious books in Jewish traditions, Marianne Schleicher starts with a critical note on the predominant size criterion of miniature books since it privileges the codex format and printing technologies in the history of Western cultures. She provides examples from a broad history of books, from clay tablets in Mesopotamian and silk scrolls in China to typographic printing in Europe, in order to illustrate how a variety of small books have served to store cultural material. While presenting religious miniature books as both texts and artifacts, she presents theoretical reflections on how processes of miniaturization facilitate individualized religiosity when the large and complex is transformed to something small and easy to handle. Although miniaturized books in Jewish religion, such as community rules, Hebrew Bible codices, and Torah codices and scrolls, may serve many different functions, the artifactual properties of the books activate sensory responses and illusions of being close to what they metonymically represent, that is, the divine words or God. In times of exile the Jews have miniaturized their religious books partly because of the portability of small books. 
Another type of miniature book that expands the understanding of different material formats are the carved wooden beads that depict events from the Christian story in the inner parts and were objects for devotion in late medieval Europe. These textual objects in the form of "prayer nuts" were used like rosaries and invited various sensory interactions. In her article, Lucy Razall explores how visual and verbal representations of the Iliad enclosed in a nutshell became widely popular in early modern England after Philemon Holland's English translation of Pliny's Natural History in 1601. As the article describes and analyzes, the image of Iliad in a nutshell became a popular motif in the literary culture that forced readers and viewers to an awareness of scale in visual and intellectual terms. The desire to condense larger works, such as the Bible, into miniature format reflected a wider anxiety about the intricate relationship between physical size and literary weightiness.

By approaching the Bible as an iconic book with attributed power and status related to its material properties, Dorina Miller Parmenter explores the genre of "thumb Bibles" that were intended for children and functioned as representations of Bibles that contained selections or summaries of the Bible texts. First produced in England starting in the seventeenth century, modified versions of them became popular in America during the nineteenth century. The latter were produced as representations of the Bible appropriate for children in their texts and illustrations that functioned as didactical tools to learn and venerate the book. When new technologies at the end of the nineteenth century allowed for the production of the whole Bible in miniature size, such as those produced by David Bryce in Glasgow, the popularity of thumb Bibles ended and the miniscule Bibles became iconic books for visual display with the physical relationship with the semantic dimension reduced. As the article argues, the thumb Bibles for children envisioned future Bible uses, while the iconic reductions of the Bible produced by Bryce relied on nostalgia and the memory of prior Bible uses. The consequence of size upon the parameters and practicalities of devotional use, technical execution, and the signification of overt or underlying ideologies is especially potent when contending with the extremes of scale expressed through miniaturized or gigantic proportions.

Focusing on the production of printed miniature Qur'ans in the late nineteenth and early twentieth century, Kristina Myrvold investigates how the influential publisher David Bryce in Scotland began printing and selling large quantities of diminutive Qur'ans intended for an 
Indian market. Although very few historical sources are available on the work and life of Bryce, preserved letters from his colleague Henry Frowde at Oxford University Press reveal how the two publishers cooperated with the production of miniature books over three decades and operated in transnational networks of book trade. Realizing the profitable business of religious books, Bryce took use of the latest printing technologies to mass-produce small facsimiles of sacred texts in the world religions for a global market. After an overview of religious approaches to printing technologies, the article describes how Bryce worked with the content, size, and appearance of miniature Qur'ans in the Arabic script. In literature of the twentieth century these mite Qur'ans became objects of fascination and were linked to Orientalist narratives of Arabs and Indian Muslim soldiers during the First World War that enmeshed the books in amuletic traditions of Islam.

Exploring the specific historical context of the First World War, Kristina Myrvold and Andreas Johansson further describe how miniature Qur'ans were distributed to Indian Muslim soldiers that served the British army in Europe. When the British entered the war in 1914 one third of their forces were Indians of the British Indian Army and many of these were Muslims from the northern part of India. The religious needs of the Indian soldiers became a concern for military and colonial authorities since religion was believed to affect the morale among soldiers stationed in Europe as well as influence the political opinion in India. British authorities tried to identify the soldiers' religious needs through various measures, including regular checks of the soldiers' letters that underwent military censorship and communicated requests for religious scriptures. The article examines how the Indian Soldiers' Fund came to operate as an important charity to obtain and distribute Qur'ans to the soldiers and consolidated donations of religious scriptures from influential persons in Britain and Europe. Even if archival sources do not elucidate any detailed information about the soldiers' uses and meanings of the miniature books, the Qur'an was attributed iconic functions to represent Muslim identities and relationships between the colonial rulers and their subjects.

In an article that starts with a questioning of intentions and purposes attributed to uses of miniature Qur'ans, Jonas Svensson provides theoretical reflections and explanations of the desirability of contemporary small versions of the Qur'ans that are mass-produced and popular as marketable commodities. In an attempt to look beyond culture-specific contexts of using the Qur'an, the article focuses on the conceptual framework of "affordances" and how potentialities and constrains 
arise when humans encounter objects and their physical properties. Using James Watts' theory of the three dimensions of scriptures to present an overview of common Muslim uses of the Qur'an, it argues that miniature Qur'ans deviate their affordances in relation to the prototypical larger Qur'ans, as representations of the larger versions, but miniaturization leads to a shift in affordances from those linked with the semantic dimension. The diminutive codices are attributed social affordances of being capable to be displayed, worn, conveyed, and given away, and the attractiveness of the books can be found in the aesthetics of size that mobilize emotions in humans.

Addressing Hindu scriptures, Jon Skarpeid examines miniature editions of the Bhagavad Gita produced by four publishers in India and Peru. Special attention is given to the paratextual properties of the books, such as title pages, prefaces, and illustrations, and how these may affect the intended reception. While providing a descriptive overview of various Bhagavad Gitas and their publishers, the article examines how the expected uses of the books are included in paratexts and instructions from the publishers. Besides an emphasis on the portability of the small books and their ability to transmit divine power by a mere presence, some of the miniature Bhagavad Gitas have additional mantras and ritual texts included in order to prescribe an ideal approach of the text as an act of religious worship. As the article suggests, some of the contemporary publishers maintain conservative views on gender and caste by incorporating illustrations that portray social hierarchies and ritual texts that by tradition are performed only by men. Other publishers have chosen to exclude verses from the Bhagavad Gita that might be considered controversial for users of the small books. These various strategies indicate how publishers communicate ideologies by including paratextual properties to small and larger books.

In the final article Yohan Yoo and Woncheol Yun examine miniature sutras in practices of Mahayana Buddhism that aim to transform and impute life into statues of Buddha. Based on the religious notions of Buddhist scriptures as embodiments of dharma and Buddha, the authors argue that various sutras are regarded as sacred beings and possess an iconicity that is believed to evoke power independently of the semantic content of the texts. After an historical overview of temple practices of installing Buddha statues by placing relics and sutras in them, the article describes how contemporary lay Buddhists in Korea activate the presence of Buddha by inserting different printed miniature sutras into the statues. The religious items have become commodified to the extent that no rituals are required for the installation 
of Buddha and it is even possible to buy statues with sutras already enclosed. Tiny sutras printed in codex format are also believed to have protective functions when kept close to the body like amulets. In these religious practices the miniature sutras function as representations of the larger texts which are considered to signify dharma.

This volume can be viewed as a first attempt to gather research studies that deal with miniaturization of books in religious traditions and may encourage further empirical and theoretical research on the material aspects of religious books. The volume addresses and makes a contribution to scholarship especially in religious studies, cultural studies, and book history, and will appeal to a broader readership with interest in religious scriptures, publishing, and miniature books.

\section{References}

Adomeit, Ruth E. 1980. Three Centuries of Thumb Bibles: A Checklist. New York: Garland.

Bondy, Louis W. 1981. Miniature Books: Their History from the Beginnings to the Present Day. London: Sheppard.

Bromer, Anne C. and Julian I. Edison. 2007. Miniature Books: 4,000 Years of Tiny Treasures. New York: Abrams.

Genette, Gerard. 1997. Paratexts: Thresholds of Interpretation. Cambridge: Cambridge University Press. https://doi.org/10.1017/CBO9780511549373

Henderson, James D. 1933. "A Lilliputian Library.” The American Book Collector IV: $145-150$.

Jaffe, Alexandra, Jannis Androutsopoulos, Mark Sebba, and Sally Johnson, eds. 2012. Orthography as Social Action: Script, Spelling, Identity and Power. Boston: De Gruyter. https://doi.org/10.1515/9781614511038

Meyer, Birgit, David Morgan, Crispin Paine, and S. Brent Plate, 2010. "The Origin and Mission of Material Religion." Religion 40: 207-211. https://doi. org/10.1016/j.religion.2010.01.010

Morgan, David, ed., 2010. Religion and Material Culture: The Matter of Belief. Abingdon: Routledge.

Myrvold, Kristina. 2007. Inside the Guru's Gate: Ritual Uses of Texts among Sikhs in Varanasi. Lund Studies in African and Asian Religions. Lund: Media-Tryck.

Myrvold, Kristina, ed. 2010. The Death of Sacred Texts: Ritual Disposal and Renovation of Texts in World Religions. Abingdon: Routledge.

Myrvold, Kristina. 2017. “'Orientalizing' Bibles in Punjab: Christian Missionaries and Book Printing in Nineteenth Century India."' In India: Research on Cultural Encounters and Representations at Linnaeus University, edited by Kristina Myrvold and Soniya Billore, 100-130. Göteborg: Makadam. 
O’Donnell Georgene. 1943. Miniaturia: The World of Small Things. Chicago: Lightner.

Shaw, Graham. 1994. "Lithography v. letter-press in India" (Part II). South Asia Library Notes \& Queries 30: 1-10.

Spielmann, Percy Edwin. 1961. Catalogue of the Library of Miniature Books. London: Edward Arnold.

Stam, Deirdre C. 2010. "Talking about 'Iconic Books' in the Terminology of Book History." Postscripts 6: 23-38.

Stark, Ulrike. 2009. An Empire of Books: The Naval Kishore Press and the Diffusion of the Printed Word in Colonial India. New Delhi: Orient Blackswan.

Veidlinger, Daniel. 2006. "When a Word is Worth a Thousand Pictures: Mahayana Influence on the Theravada Attitudes towards Writing." Numen 53: 405-447. https://doi.org/10.1163/156852706778942012

Watts, James W. 2006. "The Three Dimensions of Scriptures." Postscripts 2: 135-159.

Welsh, Doris V. 1989. A Bibliography of Miniature Books (1470-1965). New York: Kathryn I. Rickard.

Welsh, Doris V. 1987. The History of Miniature Books. New York: Fort Orange.

Yelle, Robert A. 2013. The Language of Disenchantment: Protestant Literalism and Colonial Discourse in British India. Oxford: Oxford University Press. 